\title{
Correlation of Urine Dipstick Test with Spot Urine Protein-Creatinine Ratio in Women with Preeclampsia: A Cross Sectional Study
}

\author{
K. Rekha Rani ${ }^{1}$, Tulasi Reddy ${ }^{2}$ \\ ${ }^{1,2}$ Assistant Professor, Department of Obstetrics and Gynaecology, \\ Chalmeda Anand Rao Institute of Medical Sciences \& Hospital, Karimnagar, Telangana
}

Corresponding Author: Tulasi Reddy

\begin{abstract}
Background: Preeclampsia is one of the leading causes for the maternal and perinatal morbidity and mortality. Increase level of proteinuria is worsening condition for the pregnant women with hypertension.

Objective: Our study aimed to compare urine dipstick method with $\mathrm{P} / \mathrm{C}$ ratio to know the proteinuria level in hypertensive pregnant women.

Material and Methods: This Cross-sectional study was conducted on 100 antenatal women with preeclampsia in Department of obstetrics and gynecology, CAIMS Karimnagar. Antenatal cases with pre-eclampsia of more than 20 weeks gestation were included in the study and Urinary Tract Infection, Diabetic, renal function disorder were excluded from study. After getting patients consent detailed history were taken, general physical and systemic including obstetric examination was done Association between the variable analyzed by using chi-square or fisher exact test and quantitative variable compare using ANOVA and Pearson correlation coefficient. P-value $<0.05$ considered as significant
\end{abstract}

Result: Among 100 patients admitted, there are 50 cases having mean age were $25 \pm 3.266$ Years, systolic blood pressure was $156.5 \pm 21.94 \mathrm{mmhg}$. Association between $\mathrm{P} / \mathrm{C}$ ratio and urine dipstick was statistically significant and also correlation between urine dipstick and $\mathrm{P} / \mathrm{C}$ ratio was moderately correlated $(\mathrm{r}=0.564)$ and highly significant ( $\mathrm{p}$-value $<0.05$ )

Conclusion: Our study conclude that Urine dipstick method and $\mathrm{P} / \mathrm{C}$ ratio has strong correlation between them with high accuracy, at 2+or greater level it can used to estimate significant proteinuria or spot urine $\mathrm{P} / \mathrm{C}$ ratio for screening pregnant women with suspected preeclampsia. Also, this method is convenient and cost effective for patient.

Keywords: Preeclampsia, Proteinuria, Urine Dipstick, Antenatal.

\section{INTRODUCTION}

Pre-eclampsia is a disease involving multiple systems such as renal, hepatic, neurological, coagulation and cardiovascular system etc. Hypertensive disorder of pregnancy complicates approximately 15$20 \%$ of pregnancies of which preeclampsia occurs in $2-8 \%$. Preeclampsia accounts for $15-20 \%$ of maternal mortality and a high amount of maternal morbidity. It is a major pregnancy complication causing preterm birth which is often iatrogenic, intrauterine growth restriction, abruption and intrauterine fetal demise which contribute significantly to perinatal mortality and morbidity. It is often thought of as a disorder with two components, an abnormal placental implantation with endothelial dysfunction. "According to the International Society for the Study of Hypertension in Pregnancy (ISSHP), preeclampsia, transient gestational hypertension, and gestational hypertension $(\mathrm{GH})$ are characterized by the new onset of hypertension (systolic blood pressure $\geq 140 \mathrm{mmHg}$ or diastolic blood pressure $\geq 90 \mathrm{mmHg}$ ) at or after 20 weeks of gestation." [1] 
Protein urea is an important diagnostic criterion to know the sign of worsening preeclampsia because; preeclampsia is a gestational hypertension with protein urea. Maternal fetal morbidity increases more when protein urea is severe and persistent and when it is increases most of the complication related to the pregnancy increases. Thus, for management of hypertensive pregnant women and to reduce pregnancy related complication, accurate, rapid detection of protein urea is essential.

There are various methods available to estimate protein urea, and 24 hours urinary protein estimation consider as gold standard, but this method has some limitation like, it takes time, inconvenient for patient also poor patients has to support for this test. Thus spot urine protein creatinine ratio and urine dipstick can be the alternative method to estimate protein urea.

For the initial estimation of proteinuria urine dipstick test consider as rapid screening test.[2] Some studies found that urine dipstick test has low sensitivity and specificity and sometime it gives false positive and false negative results, but when in case of urgent delivery because of bad maternal and foetal condition urine dipstick method is the alternative method to estimate proteinuria. Urine dipstick method is less expensive, easy to carry out, also it can be done by patient under the guidance of paramedical staff. $[3,4]$

Thus, present study has undertaken with aim to compare urine dipstick method and spot urine protein: creatinine ratio to estimate significant proteinuria in patient with preeclampsia.

\section{MATERIAL AND METHODS}

Study Design : This Cross-sectional study was conducted on 100 antenatal women with preeclampsia.

Study Place: Department of obstetrics and gynecology, CAIMS Karimnagar.

Study Duration: August 2020 to January 2021

\section{Inclusion Criteria}

This study will be carried on 100 randomly selected admitted antenatal cases with pre-eclampsia of more than 20 weeks gestation.

\section{Exclusion Criteria}

1. Urinary tract infection.

2. Preexisting renal or vascular disease.

3. Chronic hypertension

4. Diabetes mellitus.

After getting the informed consent, all women were examined. A detailed history was taken, general physical and systemic including obstetric examination was done. A urinary dipstick was done and in the women who showed 1+ proteinuria or more, quantitative tests for proteinuria carried out.

Visual urine dipstick test, Protein urea graded as follow

\begin{tabular}{|c|c|}
\hline Traces & $\mathbf{1 5}-\mathbf{3 0} \mathbf{~ m g} / \mathbf{d l}$ \\
\hline $1+$ & $>30 \mathbf{m g} / \mathrm{dl}$ \\
\hline $2+$ & $100 \mathrm{mg} / \mathrm{dl}$ \\
\hline $3+$ & $300 \mathrm{mg} / \mathrm{dl}$ \\
\hline $4+$ & $\geq 1000 \mathrm{mg} / \mathrm{dl}$ \\
\hline
\end{tabular}

Sample was collected for spot protein/creatinine ratio estimation, urine protein-creatinine ratio in a single voided urine specimen was obtained by dividing the urine protein concentration $(\mathrm{mg} / \mathrm{dl})$ by the urine creatinine $(\mathrm{mg} / \mathrm{dl})$.

\section{Statistical Analysis}

The data was collected in the prepared proforma and entered into Excel 2016 sheet and analysed with SPSS version 25 IBM software. Results were reported as mean, standard deviation or number percentage \& were calculated for categorical data. There were total 100 admission. Association between the variable analyzed by using chi-square or fisher exact test and quantitative variable compare using ANOVA and Pearson correlation coefficient. P-value $<0.05$ considered as significant

\section{RESULTS}

In this cross-sectional observational study, total 100 patients were recruited, and their observations were as follows. 
K. Rekha Rani et.al. Correlation of urine dipstick test with spot urine protein-creatinine ratio in women with preeclampsia: a cross sectional study

Table1: Distribution of Socio-Demographic data.

\begin{tabular}{|l|c|c|}
\hline \multicolumn{1}{|c|}{ Parameters } & Mean/No & Min-Max/Percentage \\
\hline AGE in years & $25 \pm 3.266$ & $19-34$ \\
\hline GA in weeks & $32.1 \pm 4.509$ & $3-38$ \\
\hline SBP(mmhg) & $156.5 \pm 21.945$ & $10-210$ \\
\hline DBP(mmhg) & $99 \pm 8.587$ & $90-120$ \\
\hline Gravida & \multicolumn{2}{|}{} \\
\hline Multi & 54 & 54 \\
\hline Primi & 46 & 46 \\
\hline Past History of Preeclampsia \\
\hline Yes & 19 & 19 \\
\hline No & 81 & 81 \\
\hline
\end{tabular}

Above table shows the sociodemographic distribution of data 100 patients recruited for study have their mean age $25 \pm 3.266$ (19-34 Years), systolic blood pressure was $156.5 \pm 21.945$ diastolic pressure was $99 \pm 8.587$ and $19 \%$ of the patients had history of preeclampsia.

Table 2: Mean distribution of urinary protein in urine dipstick

\begin{tabular}{|c|c|c|c|c|c|}
\hline \multirow{2}{*}{ Urine Dipstick } & \multicolumn{5}{|c|}{ Urinary Protein } \\
\cline { 2 - 4 } & Number & Mean & SD & F-value & p-value \\
\hline 0 & 4 & 519.5 & 255.038 & & \\
\hline $1+$ & 63 & 689.33 & 718.272 & & \multirow{2}{*}{10.908} \\
\hline $2+$ & 13 & 1751.46 & 1712.209 & \\
\hline $3+$ & 12 & 1830.33 & 1839.742 & & \\
\hline $4+$ & 8 & 3502 & 2575.467 & & \\
\hline
\end{tabular}

Distribution of mean urinary protein showed that as the urine dipstick increases urinary protein also increasing, and the difference between mean urinary protein among the urine dipstick were statistically significant.

Table 3: Distribution of $P / C$ ratio in Urine Dipstick

\begin{tabular}{|c|c|c|c|c|c|}
\hline Urine Dipstick & \multicolumn{2}{|c|}{ P/C Ratio interval } & Total & Fisher Exact & \multirow{2}{*}{ P-value } \\
\cline { 2 - 4 } & $\langle\mathbf{0 . 3 0}$ & $\boldsymbol{> 0 . 3 0}$ & & & \\
\hline 0 & 0 & 4 & 4 & & \\
\hline $1+$ & 14 & 49 & 63 & \multirow{2}{*}{$20.667 * *$} & \multirow{2}{*}{$0.002(\mathrm{Sig})$} \\
\hline $2+$ & 3 & 10 & 13 & \\
\hline $3+$ & 3 & 9 & 12 & & \\
\hline $4+$ & 0 & 8 & 8 & & \\
\hline Total & $\mathbf{2 0}$ & $\mathbf{8 0}$ & $\mathbf{1 0 0}$ & & \\
\hline \multicolumn{7}{|l}{} & & \\
\hline
\end{tabular}

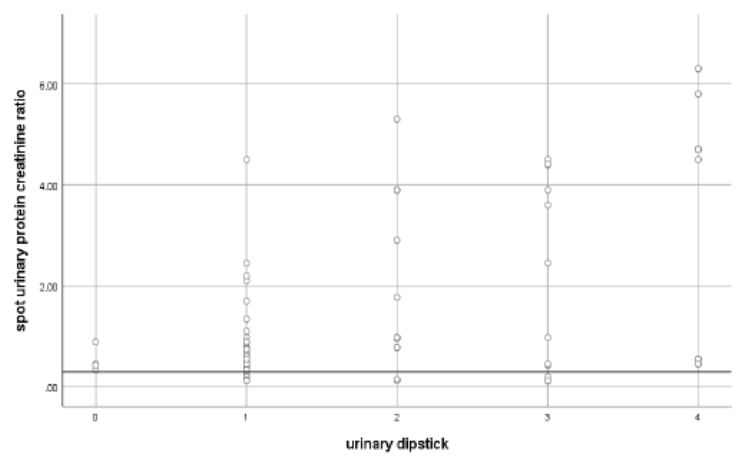

Figure 1: Correlation between $\mathrm{P} / \mathrm{C}$ ratio in Urine Dipstick.

Association between $\mathrm{P} / \mathrm{C}$ ratio and urine dipstick was statistically significant and also correlation between urine dipstick and $\mathrm{P} / \mathrm{C}$ ratio was moderately correlated $(\mathrm{r}=$ $0.564)$ and highly significant ( $p$-value $<0.05)$ at $5 \%$ level of Significance. Correlation between urine dipstick and P/C ratio shown in bellow figure 1

Table 4: Diagnostic test characteristics at different dipstick grades to predict proteinuria of 300mg/day or more

\begin{tabular}{|l|c|c|c|c|}
\hline Diagnostic Characteristics & $\mathbf{1 +}$ & $\mathbf{2 +}$ & $\mathbf{3 +}$ & $\mathbf{4 +}$ \\
\hline Sensitivity & $57.83 \%$ & $13.75 \%$ & $11.25 \%$ & $10.00 \%$ \\
\hline Specificity & $25.00 \%$ & $90.00 \%$ & $85.00 \%$ & $100.00 \%$ \\
\hline PPV & $76.19 \%$ & $84.62 \%$ & $75.00 \%$ & $100.00 \%$ \\
\hline NPV & $12.50 \%$ & $20.69 \%$ & $19.32 \%$ & $21.74 \%$ \\
\hline Positive Likelihood Ratio & 0.77 & 1.38 & 0.75 & - \\
\hline Negative Likelihood Ratio & 1.69 & 0.96 & 1.04 & 0.9 \\
\hline
\end{tabular}

Above table describes diagnostic accuracy of urine dipstick test to detect proteinuria in preeclampsia patients at various grades. 1+ was found to be best cutoff to detect $300 \mathrm{mg}$ of protein excretion per day with sensitivity and specificity of
$57 \%$ and $25 \%$. At other cutoffs specificity improves, but sensitivity is compromised. Linear relationship analysis between different dipstick values and 24-hour total protein excretion showed regression coefficient $(R 2)$ 0.33, which indicated poor 
relationship (value close to 1 indicate strong relationship).

\section{DISCUSSION}

In this study cross sectional study 100 antenatal cases of pre eclampsia with urinary dipstick value $\geq 1+$ were selected. General physical and obstetric examination was done for all. $24 \mathrm{hr}$ urinary sample and a next morning random sample for urinary PCR was collected from all the patients. Amount of proteinuria was estimated by turbimetric method using sulphosalicylic acid and urinary creatinine was calculated by Jaffe's method. Urinary Protein Creatinine Ratio $\geq 0.3$ is taken as significant proteinuria.

\section{Age}

Mean age of all the patients in this present study was $25 \pm 3.266$ years with maximum age was 34 years and minimum age was 19 years, this mean age group was observed by the study conducted by Pallavee $\mathrm{P}$ et al. ${ }^{[5]}$, in their study they have observe mean age was $25.35 \pm 3.56$ Years

\section{* Gestational Age}

Present study findings for gestational age was32.1 \pm 4.509 weeks which was less than the study by Pallavee $P$ et al., which was $36.20 \pm 2.31$ weeks.

\section{Systolic and Diastolic Blood Pressure}

Systolic and Diastolic Blood pressure in present study was found to be $156.5 \pm 21.945$ and $99 \pm 8.587$ so this observation was similar to the study conducted by Sapna V. Amin et al (2014) ${ }^{[6]}$

\section{* P/C ratio and Urine Dipstick}

The urine dipstick test is a screening assay, which could detect positive cases (true disease). Test dipstick method and P/C ratio shows the positive and strong correlation with $\mathrm{r}=0.564$, p-value $<0.05$. Due to the high sensitivity of this test, the 1 + urine dipstick level appears to be useful as a screening test for spot urine samples for the presence of protein if the patient is having preeclampsia. At the $2+$ level, urine dipstick appears to be more specific for detection of proteinuria. From the present results it shows that test dipstick can be in the routine screening of normal pregnant woman. In study conducted by Pallavi $\mathrm{P}$ et al correlation between $\mathrm{P} / \mathrm{C}$ ratio and urine dipstick was 0.41 , means it was moderately correlated.

Our observation can recommend that if the patients with suspected preeclampsia, initially can go for the dipstick urine analysis to understand proteinuria level in the urine. If the urinalysis has $2+$ protein or greater, the patient most likely has significant proteinuria. Urine dipstick method in our observation tells us that $\mathrm{P} / \mathrm{C}$ ration $>0.3$ has significant proteinuria thus by using this method we can estimate maximum proteinuria level instead of going for another method or test which is more costlier than present method.

On the basis of degree of proteinuria we can classify patients in different categories in order to decide which patients require further investigation. In present study we observed that the correlation between urine dipstick and $\mathrm{P} / \mathrm{C}$ ratio was strongly correlated with each other. But this method also has some limitation for urine dipstick method has cutoff value $1+$ level of test dipstick, it may require further elucidation with quantitative testing, but $2+$ level on the dipstick, most patients would be having significant proteinuria. Thus from overall we can suggest that at initial level patient with preeclampsia for normal pregnancy can go for urine dipstick method to know the degree of proteinuria level, which most convenient technique for patients.

\section{CONCLUSION}

On the basis of above observation, we can conclude that Urine dipstick method and $\mathrm{P} / \mathrm{C}$ ratio has strong correlation between them with high accuracy, at $2+$ or greater level it can used to estimate significant proteinuria or spot urine $\mathrm{P} / \mathrm{C}$ ratio for screening pregnant women with suspected 
preeclampsia. Also, this method is convenient and cost effective for patient.

\section{Acknowledgement: None}

\section{Conflict of Interest: None}

\section{Source of Funding: None}

\section{Ethical Approval: Approved}

\section{REFERENCES}

1. Brown, M.A.; Magee, L.A.; Kenny, L.C.; Karumanchi, S.A.; McCarthy, F.P.; Saito, S.; Hall, D.R.; Warren, C.E.; Adoyi, G.; Ishaku, S. International Society for the Study of Hypertension in Pregnancy (ISSHP). Hypertensive Disorders of Pregnancy: ISSHP Classification, Diagnosis, and Management Recommendations for International Practice. Hypertension 2018, 72, 24-43.

2. Kuklina, E.V.; Ayala, C.; Callaghan, W.M. Hypertensive disorders and severe obstetric morbidity in the United States. Obstet. Gynecol. 2009, 113, 1299-1306.

3. Phelan LK, Brown MA, Davis GK, Mangos G. A prospective study of the impact of automated dipstick urinalysis on the diagnosis of pre-eclampsia. Hypertens Pregnancy 2004; 23: 135-42.

4. Poon, L.C.; Shennan, A.; Hyett, J.A.; Kapur, A.; Hadar, E.; Divakar, H.;
McAuli_e, F.; da Silva Costa, F.; von Dadelszen, P.; McIntyre, H.D.; et al. The International Federation of Gynecology and Obstetrics (FIGO) initiative on preeclampsia: A pragmatic guide for firsttrimester screening and prevention. Int. J. Gynaecol. Obstet. 2019, 145, 1-33. [Cross Ref]

5. Q. Huang, Y. Gao, Y. Yu, W. Wang, S. Wang, and M. Zhong, "Urinary spot albumin: creatinine ratio for documenting proteinuria in women with preeclampsia," Reviews in Obstetrics \& Gynecology, vol. 5, no. 1, pp. 9-15, 2012.

6. Pallavee P, Nischintha S. A comparison of urine dipstick test with spot urine proteincreatinine ratio and 24-hour urine protein excretion in women with preeclampsia. Int $\mathbf{J}$ Reprod Contracept ObstetGynecol 2015; 4:589-94.

7. Amin SV, Illipilla S, Hebbar S, Rai L, Kumar P, Pai MV. Quantifying proteinuria inhypertensive disorders of pregnancy. Int $\mathbf{J}$ Hypertens. 2014;2014:941408. doi: 10.1155/2014/941408. Epub 2014 Sep 16. PMID: 25302114; PMCID: PMC4181784.

How to cite this article: K. Rekha Rani, Reddy T. Correlation of urine dipstick test with spot urine protein-creatinine ratio in women with preeclampsia: a cross sectional study. Gal Int $J$ Health Sci Res. 2021; 6(3): 70-74. DOI: https://doi.org/10.52403/gijhsr.20210711 